\title{
ASPECTOS BIOLÓGICOS DE Chrysoperla externa (Hagen, 1861) (Neuroptera: Chrysopidae) ALIMENTADA COM Planococcus citri (Risso, 1813) (Hemiptera: Pseudococcidae) E Toxoptera citricida (Kirkaldy, 1907) (Hemiptera: Aphididae)
}

\author{
Biological aspects of Chrysoperla externa (Hagen, 1861) (Neuroptera: Chrysopidae) \\ fed with Planococcus citri (Risso, 1813) (Hemiptera: Pseudococcidae) \\ and Toxoptera citricida (Kirkaldy, 1907) (Hemiptera: Aphididae)
}

\author{
Jean Patrick Bonani ${ }^{1}$, Brígida Souza ${ }^{2}$, Lenira Viana Costa Santa-Cecília ${ }^{3}$, Lilian Roberta Batista Correa ${ }^{4}$
}

\begin{abstract}
RESUMO
O ecossistema citrícola abriga muitas espécies de inimigos naturais, entre eles Chrysoperla externa (Hagen, 1861) que apresenta um grande potencial como agente de controle biológico de pragas. Neste trabalho, objetivou-se avaliar o efeito das presas Planococcus citri (Risso, 1813) e Toxoptera citricida (Kirkaldy, 1907) sobre o desenvolvimento das fases de larva e pupa de $C$. externa. O ensaio foi conduzido em sala climatizada a uma temperatura de $25 \pm 1^{\circ} \mathrm{C}, 70 \pm 10 \% \mathrm{UR}$ e fotofase de 12 horas, sendo os tratamentos constituídos pelo fornecimento contínuo e alternado dessas duas presas em cada ínstar do predador, além de ovos de Anagasta kuehniella (Zeller, 1879), utilizados para fins de comparação. Foram avaliados o tempo de vida e a viabilidade das fases de larva, pupa e do período larva-adulto de $C$. externa. Constatou-se que $T$. citricida fornecido isoladamente ao longo do desenvolvimento larval ou em dois ínstares consecutivos do predador, não foi uma presa adequada, constatando-se 100\% de mortalidade no período larva-adulto. Quando as larvas alimentaram-se de $P$. citri fornecida em dois ínstares do predador, a viabilidade no período larva-adulto foi semelhante à dieta constituída por apenas ovos de A. kuehniella, exceto quando se alimentaram de $T$. citricida no primeiro ínstar.
\end{abstract}

Termos para indexação: Crisopídeo, pulgão, cochonilha-branca, citros, biologia.

\section{ABSTRACT}

The citrus-growing ecosystem houses a great deal of species of natural enemies, among them Chrysoperla externa (Hagen, 1861), which presents a great potential for use in the biological control of pests. The aim of this work was to evaluate the effects of the preys Planococcus citri (Risso, 1813) and Toxoptera citricida (Kirkaldy, 1907) on the development of larva and pupa of $C$. externa. The trial was carried out in an acclimatized room at $25 \pm 1^{\circ} \mathrm{C}, 70 \pm 10 \% \mathrm{RH}$ and 12 -hour photophase, the treatments consisting of the continuous and alternate supply of those two preys in each instar of the predator, in addition to eggs of Anagasta kuehniella (Zeller, 1879) utilized for comparison purposes. Both the white mealybug and the aphids were given in sufficient amounts to the $C$. externa larvae to be able to feed ad libitum. The lifetime and the survival rate of the phases of larva, pupa and the larval-adult period of $C$. externa were evaluated. It was found that $T$. citricida given either singly along the larval development or in two consecutive instars of the predator was not an adequate prey, $100 \%$ of mortality over the larval-adult period being found. When the larvae fed on $P$. citri, given in two instars of the predator, the survival rate in the larval-adult period was similar to the diet constituted of only $A$. kuehniella eggs, except when fed with $T$. citricida in the first instar.

Index terms: Green lacewing, aphid, white mealybug, citrus, biology.

(Recebido em 10 de agosto de 2007 e aprovado em 24 de abril de 2008)

\section{INTRODUÇÃO}

Entre as pragas da cultura de citros, destaca-se a cochonilha-branca Planococcus citri (Risso, 1813) (Hemiptera: Pseudococcidae) e o pulgão-preto-dos-citros, Toxoptera citricida (Kirkaldy, 1907) (Hemiptera: Aphididae) que, em razão da sucção contínua de seiva, causam perdas significativas na produtividade da cultura. As cochonilhas ocasionam deformações ou queda de frutos e desfolhamento da planta (GRAVENA, 2003) e os pulgões constituem-se em eficientes vetores do vírus da tristeza

\footnotetext{
${ }^{1}$ Engenheiro Agrônomo, Doutorando em Entomologia - Departamento de Entomologia, Fitopatologia e Zoologia Agrícola - Escola Superior de Agricultura Luiz de Queiroz/ESALQ - Universidade de São Paulo/USP - Avenida Pádua Dias, 11 - Cx. P. 9 - 13418-900 - Piracicaba, SP - jpbonani@esalq.usp.br 2Engenheira Agrônoma, Doutora em Entomologia - Departamento de Entomologia/DEN - Universidade Federal de Lavras/UFLA - Cx. P. 3037 - 37200 000 - Lavras, MG - brgsouza@ufla.br

${ }^{3}$ Engenheira Agrônoma, Doutora em Entomologia - Centro Tecnológico do Sul de Minas/CTSM - Laboratório de Controle Biológico de Pragas - Instituto Mineiro de Agropecuária/IMA - Empresa de Pesquisa Agropecuária de Minas Gerais/EPAMIG - Campus da UFLA - Cx. P. 176 - $37200-000$ - Lavras, MG scecilia@epamig.ufla.br

${ }^{4}$ Bióloga, Doutoranda em Entomologia Agrícola - Departamento de Fitossanidade - Universidade Estadual Paulista/UNESP - Via de Acesso Professor Paulo Donato Castellane, s/n - 14884-900 - Jaboticabal, SP - robertaento@yahoo.com.br
} 
dos citros (CTV), causando declínio rápido das árvores. Também pode afetar o conteúdo de açúcares das variedades de laranja (MICHAUD, 1998), além de se constituir em um potencial vetor do vírus da morte súbita dos citros. Danos indiretos podem ser ocasionados por ambos os hemípteros em razão da eliminação do honeydew, que proporciona a incidência do fungo, Capinodium citri Berk \& Desm., que dificulta ou mesmo impede a fotossíntese (GRAVENA, 2003).

O uso de agentes de controle biológico é uma das alternativas eficientes para a redução da densidade populacional de artrópodes-praga. Desde o final do século $\mathrm{XX}$, os crisopídeos (Neuroptera: Chrysopidae) têm despertado atenção quanto ao seu uso no controle populacional de insetos e ácaros-praga (CARVALHO \& SOUZA, 2000). No Brasil, boa parte dos estudos desenvolvidos com crisopídeos refere-se a Chrysoperla externa (Hagen, 1861), uma espécie Neotropical que se destaca pela voracidade de suas larvas e elevada capacidade reprodutiva, ocorrendo naturalmente em várias culturas de interesse econômico, dentre elas os citros (FREITAS, 2001; SOUZA \& CARVALHO, 2002).

No ecossistema citrícola esses predadores têm como alvo cochonilhas, pulgões, moscas-brancas e ácaros, permitindo sua ocorrência em todos os meses do ano (CARVALHO \& SOUZA, 2000; FREITAS, 2002). Michaud (2001) relataram que os crisopídeos podem reduzir as colônias de $T$. citricida antes do surgimento das formas aladas, evitando a dispersão e possível formação de uma nova colônia. Gonçalves-Gervásio \& Santa-Cecília (2001) observaram que $C$. externa apresenta potencial de utilização no controle da cochonilha Dysmicoccus brevipes (Cockerell, 1893) (Hemiptera: Pseudococcidae) diante do elevado número de ninfas e adultos predados. Conforme Gravena (1990), larvas de C. externa predam preferencialmente ovos e ninfas de primeiro e segundo ínstares da cochonilha Parlatoria cinerea Doane \& Hadden, 1909 (Hemiptera: Diaspididae), apresentando elevada capacidade de consumo.

A conquista da proeminente posição da citricultura brasileira se vincula, no entanto, ao uso de alternativas aos freqüentes problemas de ordem fitossanitária que se interpõem à etapa agrícola. Buscando métodos alternativos para o controle de pragas agrícolas e considerando que os crisopídeos têm sido relatados como de ocorrência freqüente em ecossistemas citrícolas (SOUZA, 1999), conduziu-se este trabalho, com o objetivo de estudar o efeito das presas T. citricida e $P$. citri, sobre o desenvolvimento das fases de larva e pupa de $C$. externa.

\section{MATERIALE MÉTODOS}

O trabalho foi desenvolvido no Laboratório de Controle Biológico de Pragas da Empresa de Pesquisa Agropecuária de Minas Gerais-EPAMIG/CTSM/EcoCentro em Lavras, MG.

Os crisopídeos foram provenientes da criação existente no Laboratório de Biologia de Insetos da Universidade Federal de Lavras - UFLA, Lavras, MG, onde as larvas são alimentadas com ovos de Anagasta kuehniella (Zeller, 1879) (Lepidoptera: Pyralidae) e os adultos com uma dieta à base de lêvedo de cerveja e mel, sendo mantidos a $25 \pm 1^{\circ} \mathrm{C}$, UR de $70 \pm 10 \%$ e fotofase de 12 horas. Ovos da geração $\mathrm{F}_{3}$, com até 24 horas de idade, foram individualizados e mantidos em câmaras climatizadas sob as mesmas condições ambientais anteriormente descritas, até a eclosão das larvas.

As cochonilhas foram obtidas de criações mantidas em frutos de laranjeira [Citrus sinensis (L.) Osbeck cultivar Baía] no laboratório da EPAMIG, em condições climáticas semelhantes às descritas anteriormente. Os pulgões foram obtidos de brotações de laranjeiras do mesmo cultivar, provenientes de área do pomar de frutíferas da UFLA mantida sem aplicações de produtos fitossanitários, sendo coletados diariamente e independentemente do seu estágio de desenvolvimento (ninfas, adultos ápteros e alados).

Larvas de $C$. externa recém-eclodidas foram transferidas para placas de Petri (5 cm de diâmetro), contendo discos foliares ( $4 \mathrm{~cm}$ de diâmetro) de $C$. sinensis cultivar Baía, mantidos sobre uma lâmina de cerca de $5 \mathrm{~mm}$ de ágarágua (1\%) e utilizados como substrato para alimentação das cochonilhas e pulgões. As placas foram vedadas com filme plástico de Poli Cloreto de Vinila (PVC) e acondicionadas a $25 \pm 1^{\circ} \mathrm{C}, 70 \pm 10 \%$ de umidade relativa e 12 horas de fotofase.

$\mathrm{O}$ experimento constou de nove tratamentos (Tabela 1), com 30 repetições constituídas por uma larva do predador, utilizando-se um tratamento controle, constituído por ovos de A. kuehniella por ser uma dieta tradicionalmente utilizada nas criações de crisopídeos em laboratório (CARVALHO \& SOUZA, 2000). As presas foram fornecidas diariamente e "ad libitum" às larvas de $C$. externa. As cochonilhas e os pulgões foram fornecidos nas fases de ninfa e adulta, indiscriminadamente.

Elaboraram-se curvas de sobrevivência para cada ínstar de C. externa em função dos tratamentos, utilizandose o estimador Kaplan-Meier (COLOSIMO, 2001). Considerou-se como tempo mediano de vida o período no qual a maioria das larvas passou para o ínstar ou estágio subseqüente, ou morreram. A probabilidade de sobrevivência foi considerada como o percentual de larvas que não mudaram de ínstar ou não morreram. Os dados de 
Tabela 1 - Composição dos tratamentos conforme o tipo de presa fornecida nos três ínstares de Chrysoperla externa.

\begin{tabular}{|c|c|c|c|}
\hline \multirow{2}{*}{ Tratamentos } & \multicolumn{3}{|c|}{ Ínstares do predador } \\
\hline & $1^{\mathrm{o}}$ & $2^{\underline{o}}$ & $3^{\mathrm{o}}$ \\
\hline 1 & $\begin{array}{c}\text { Ovos de Anagasta } \\
\text { kuehniella }\end{array}$ & $\begin{array}{c}\text { Ovos de Anagasta } \\
\text { kuehniella }\end{array}$ & $\begin{array}{c}\text { Ovos de Anagasta } \\
\text { kuehniella }\end{array}$ \\
\hline 2 & Planococcus citri & Planococcus citri & Planococcus citri \\
\hline 3 & Toxoptera citricida & Toxoptera citricida & Toxoptera citricida \\
\hline 4 & Planococcus citri & Planococcus citri & Toxoptera citricida \\
\hline 5 & Toxoptera citricida & Planococcus citri & Planococcus citri \\
\hline 6 & Toxoptera citricida & Toxoptera citricida & Planococcus citri \\
\hline 7 & Planococcus citri & Toxoptera citricida & Toxoptera citricida \\
\hline 8 & Planococcus citri & Toxoptera citricida & Planococcus citri \\
\hline 9 & Toxoptera citricida & Planococcus citri & Toxoptera citricida \\
\hline
\end{tabular}

duração da fase larval foram transformados em $\sqrt{\mathrm{x}+1}$ e as médias comparadas pelo teste de Tukey a $5 \%$ de significância. Avaliaram-se as viabilidades das fases de larva, pupa e do período larva-adulto, analisadas pela estimativa das proporções, com intervalo de confiança de $95 \%$.

\section{RESULTADOS E DISCUSSÃO}

\section{Desenvolvimento da fase larval}

Quando alimentadas com ovos de A. kuehniella (Tratamento 1 - A, A, A), 63,4\% das larvas de primeiro ínstar de C. externa mudaram para o estádio seguinte no quarto dia e a última delas mudou de ínstar no sétimo dia (Figura 1A). Já no segundo ínstar, constatou-se um maior número de larvas com um tempo mediano de vida de três dias, e uma duração máxima de quatro dias. No terceiro ínstar, o tempo mediano foi de três dias, apesar de 48,3\% das larvas ainda se encontrarem nesse estádio.

Quando as larvas foram alimentadas apenas com cochonilhas (Tratamento 2 - C, C, C), o tempo mediano no primeiro ínstar foi de quatro dias, no qual a maioria delas passou para o segundo ínstar. Do quinto ao $11^{\circ} \mathrm{dia}$ nenhuma larva mudou de ínstar, e no $12^{\circ}$ dia, a última larva passou para o ínstar seguinte (Figura 1B). No segundo ínstar, o tempo mediano foi de quatro dias e, de todas as larvas que sobreviveram além do sexto dia, nenhuma atingiu o ínstar seguinte. Embora os dois primeiros ínstares tenham apresentado o mesmo tempo mediano de vida (quatro dias) e a mesma probabilidade de sobrevivência $(23,3 \%)$, no primeiro, nenhuma larva morreu, enquanto que no segundo, a dieta ingerida ocasionou mortes. Para o terceiro estádio, o tempo mediano foi de cinco dias, quando $40 \%$ das larvas passaram para a fase de pupa, sendo que, entre as remanescentes, a última morreu no $11^{\circ}$ dia.

Quando se alimentaram do pulgão-preto-dos-citros (Tratamento 3 - P, P, P) (Figura 1C), o tempo mediano de vida no primeiro ínstar foi de quatro dias, não sendo registrada nenhuma morte nesse estádio de desenvolvimento. No segundo ínstar, o tempo mediano também foi de quatro dias e após o quinto dia, todas as larvas até então sobreviventes morreram.

O tempo mediano de vida no primeiro ínstar de larvas alimentadas com a cochonilha $P$. citri (Tratamento 4 - C, C, P), foi de cinco dias, quando foi registrado maior número de mudanças de ínstar (Figura 1D). O tempo mediano de vida no segundo ínstar foi de quatro dias, sendo um estádio marcado por um grande número de mortes, além de ser o mais prolongado dos três ínstares. No último estádio, as larvas passaram a receber o pulgão T. citricida como alimento e apresentaram um tempo mediano de vida de sete dias.

Quando submetidas ao Tratamento 5 (P, C, C), as larvas de primeiro ínstar, apresentaram um tempo mediano de vida de quatro dias (Figura 1E). Esse ínstar foi relativamente curto e nenhuma das larvas permaneceu nesse estádio além do quinto dia. Ao contrário do primeiro estádio, o segundo foi mais prolongado com uma duração 
que atingiu treze dias. $\mathrm{O}$ tempo mediano de vida, contudo, ocorreu no sexto dia, quando a maioria das larvas passou para o terceiro ínstar. Nesse último estádio, o tempo mediano foi de sete dias, ocasião em que ocorreu o maior número de mortes.

O tempo mediano para o primeiro ínstar de larvas submetidas ao Tratamento $6(\mathrm{P}, \mathrm{P}, \mathrm{C})$ foi de quatro dias, ocasião em que a maioria das larvas mudou de ínstar (Figura 1F). No segundo ínstar, a maior concentração de larvas em processo de ecdise ocorreu no quarto dia, e no terceiro ínstar, no oitavo dia.

Quando as larvas foram submetidas ao Tratamento 7 (C, P, P), apresentaram um tempo mediano de vida de cinco dias no primeiro ínstar (Figura 1G). No segundo ínstar, as larvas apresentaram um tempo mediano de quatro dias, sendo o ínstar mais prolongado em relação aos demais tratamentos, atingindo 17 dias. $\mathrm{O}$ terceiro ínstar também foi o mais prolongado quando comparado à duração desse estádio nos demais tratamentos, apresentando um tempo mediano de oito dias e tempo máximo de 25 dias. Em conseqüência desses prolongamentos nos ínstares, esse tratamento foi o que apresentou o maior período larval em relação aos demais.
Quando submetidas ao Tratamento 8 (C, P, C), a maior concentração de ecdises do primeiro ínstar ocorreu no quinto dia (Figura 1H). No segundo ínstar, o tempo mediano foi de quatro dias e, entre todos os tratamentos, este ínstar foi o que apresentou o maior percentual $(92,6 \%)$ de larvas passando para o terceiro estádio, caracterizando maior uniformidade no ritmo de desenvolvimento das larvas de $C$. externa. Com um tempo mediano de sete dias, o terceiro ínstar desse tratamento apresentou uma duração máxima de onze dias, quando foi registrada a morte da última larva.

O período em que ocorreu o maior número de ecdises no primeiro ínstar de larvas submetidas ao Tratamento 9 (P, C, P) foi o sexto dia (Figura 1I). O segundo ínstar teve uma duração máxima de 16 dias, quando se verificou a ecdise da última larva, porém, o tempo mediano de vida foi de seis dias, marcado pelo maior número de larvas que mudaram de ínstar. O terceiro estádio apresentou uma curva de sobrevivência praticamente similar ao ínstar anterior com um tempo mediano de vida de sete dias, e uma duração máxima de 13 dias, quando ocorreu a única morte verificada nesse estádio.

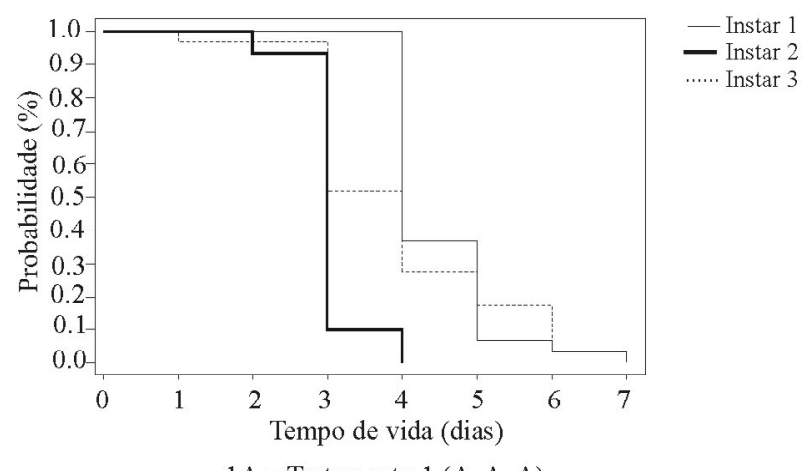

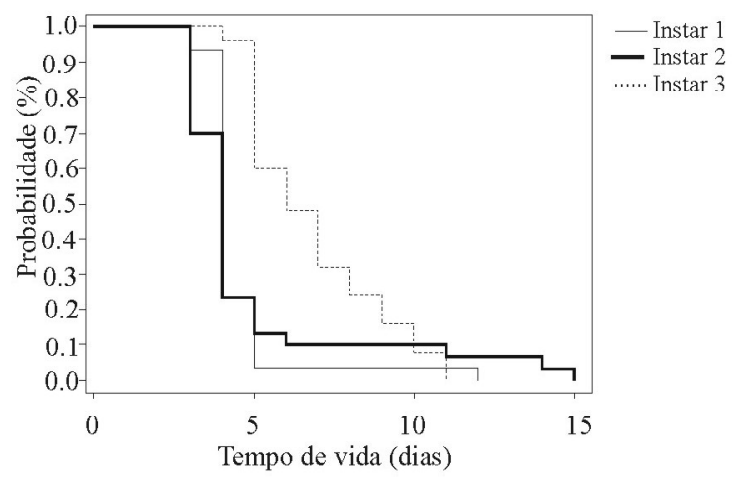

$1 \mathrm{~B}=$ Tratamento $2(\mathrm{C}, \mathrm{C}, \mathrm{C})$

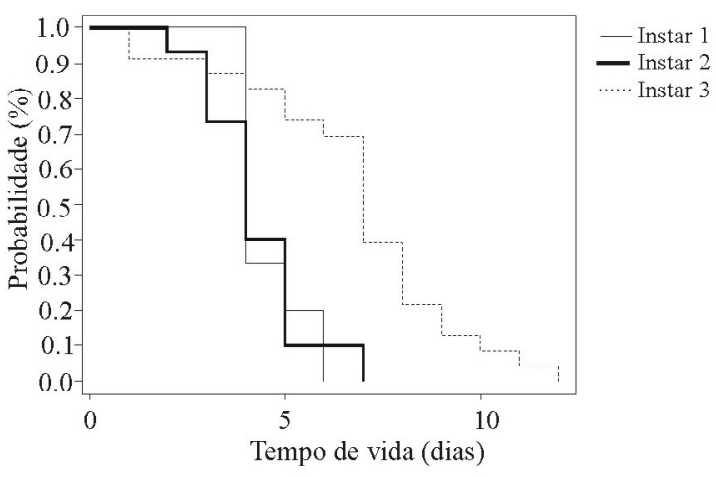

$1 \mathrm{C}=$ Tratamento $3(\mathrm{P}, \mathrm{P}, \mathrm{P})$

Continuação... 
Figura 1 - Continuação...
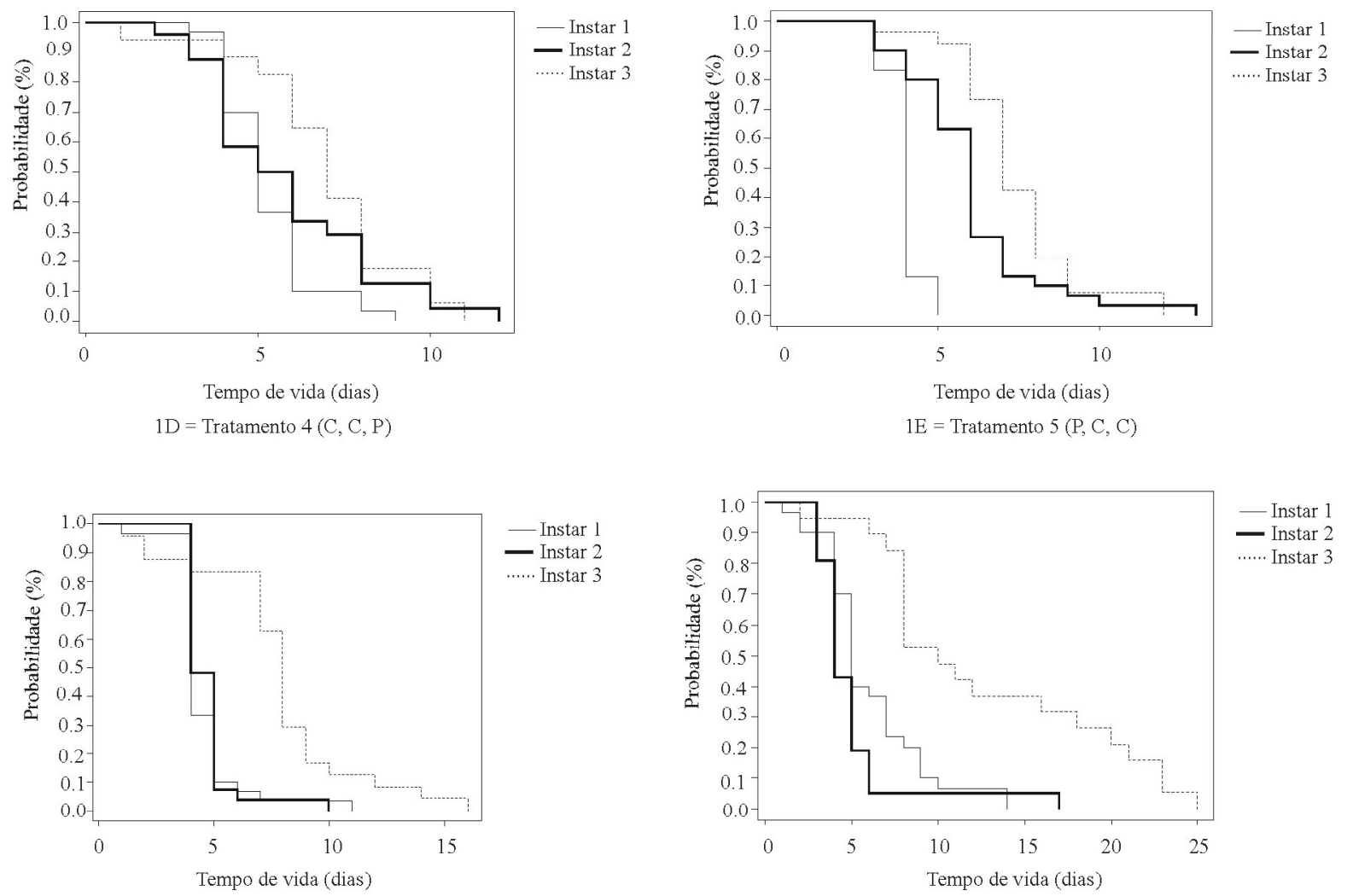

$1 \mathrm{~F}=$ Tratamento $6(\mathrm{P}, \mathrm{P}, \mathrm{C})$

$1 \mathrm{G}=$ Tratamento $7(\mathrm{C}, \mathrm{P}, \mathrm{P})$
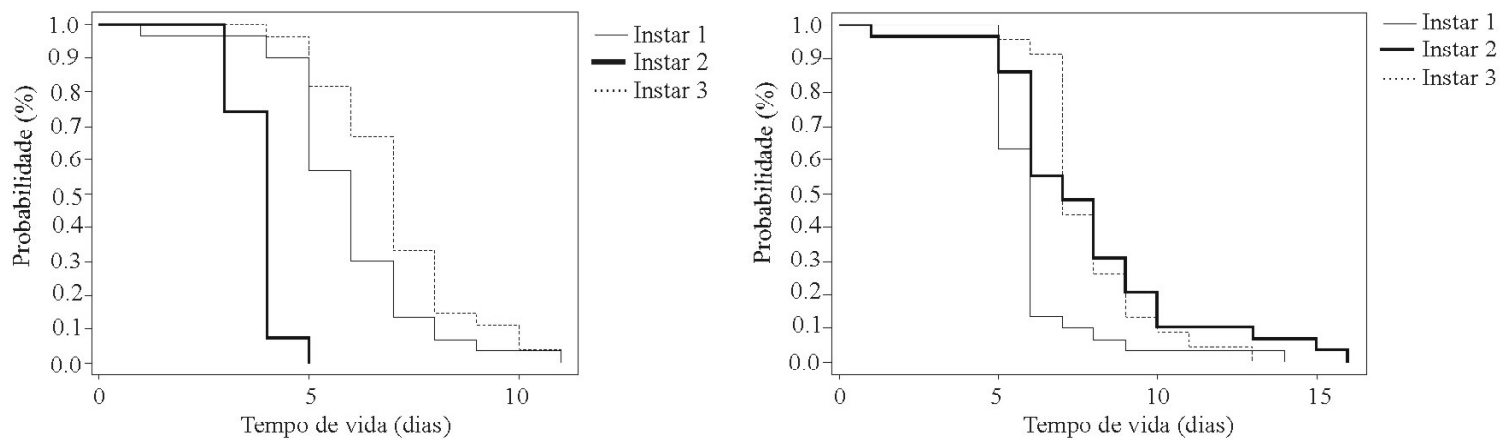

$1 \mathrm{H}=$ Tratamento $8(\mathrm{C}, \mathrm{P}, \mathrm{C})$

$1 \mathrm{I}=$ Tratamento $9(\mathrm{P}, \mathrm{C}, \mathrm{P})$

Figura 1 - Curvas de sobrevivência para o tempo mediano de vida (dias) dos três ínstares de Chrysoperla externa alimentada com Planococcus citri, Toxoptera citricida e ovos de Anagasta kuehniella. Temperatura de $25 \pm 1^{\circ} \mathrm{C}$, UR 70 $\pm 10 \%$ e fotofase de 12 horas. Lavras, MG, 2004. A) Tratamento 1 (A, A, A); B) Tratamento 2 (C, C, C); C) Tratamento 3 (P, $\mathrm{P}, \mathrm{P})$; D) Tratamento 4 (C, C, P); E) Tratamento $5(\mathrm{P}, \mathrm{C}, \mathrm{C}) ; \mathrm{F})$ Tratamento 6 (P, P, C); G) Tratamento 7 (C, P, P); H) Tratamento 8 (C, P, C) e I) Tratamento 9 (P, C, P). Letras entre parênteses indicam as presas fornecidas no $1^{\circ}, 2^{\circ}$ e $3^{\circ}$ ínstares de C. externa, respectivamente, a saber: A - ovos de A. kuehniella; C - cochonilha P. citri e P - pulgão T. citricida. 
A duração da fase larval foi afetada pelo tipo de dieta fornecida em cada ínstar do predador (Tabela 2). Quando as larvas foram alimentadas apenas com P. citri, houve um prolongamento da duração dessa fase em relação àquelas que receberam ovos de A. kuehniella. Contudo, observou-se que a cochonilha, quando fornecida em todos os ínstares de C. externa, ocasionou uma redução nesse período em relação às larvas que tiveram essa presa incluída na sua dieta em alternância com o pulgão $T$. citricida. Por outro lado, todas as larvas que receberam somente o pulgão morreram antes de completar a fase larval.

\section{Viabilidade das fases imaturas}

A viabilidade da fase larval foi afetada pelo tipo de dieta fornecida em cada ínstar do predador, oscilando de
$0,0 \%$ a $80,0 \%$ (Tabela 3 ). Os tratamentos 2,5 e 9 ocasionaram maior viabilidade larval quando comparados aos demais, não diferindo do tratamento 1 , no qual foram utilizados ovos de A. kuehniella. Esses resultados mostram que as larvas de $C$. externa apresentaram maior viabilidade quando se alimentaram somente de $P$. citri ao longo de seu desenvolvimento ou quando predaram esse pseudococcídeo no segundo, ou no segundo e terceiro ínstares, e $T$. citricida nos demais estádios.

Os tratamentos 4, 6, 7 e 8 acarretaram viabilidades entre 37 e $60 \%$. O tratamento 3, constituído unicamente por T. citricida, causou $100 \%$ de mortalidade das larvas, provavelmente por se tratar de uma presa nutricionalmente inadequada, ou em razão de algum efeito fisiológico

Tabela 2 - Duração média ( \pm EP) da fase larval de Chrysoperla externa alimentada com Planococcus citri, Toxoptera citricida e ovos de Anagasta kuehniella. Temperatura de $25 \pm 1^{\circ} \mathrm{C}$, UR $70 \pm 10 \%$ e fotofase de 12 horas. Lavras, MG, 2004.

\begin{tabular}{|c|c|c|c|c|}
\hline \multirow{2}{*}{ Tratamento } & \multicolumn{3}{|c|}{ Presa consumida } & \multirow{2}{*}{$\begin{array}{c}\text { Duração da } \\
\text { fase larval }\end{array}$} \\
\hline & $1^{\circ}$ ínstar & $2^{-}$ínstar & $3^{\circ}$ ínstar & \\
\hline 1 & A. kuehniella & A. kuehniella & A. kuehniella & $11,46 \pm 0,29 d$ \\
\hline 2 & P. citri & P. citri & P. citri & $14,29 \pm 0,48 \mathrm{c}$ \\
\hline 3 & T. citricida & T. citricida & T. citricida & -- \\
\hline 4 & P. citri & P. citri & T. citricida & $17,47 \pm 0,43 b$ \\
\hline 5 & T. citricida & P. citri & P. citri & $17,0 \pm 0,48 b$ \\
\hline 6 & T. citricida & T. citricida & P. citri & $17,41 \pm 0,47 b$ \\
\hline 7 & P. citri & T. citricida & T. citricida & $17,27 \pm 0,59 b$ \\
\hline 8 & P. citri & T. citricida & P. citri & $16,61 \pm 0,44 b$ \\
\hline 9 & T. citricida & P. citri & T. citricida & $20,82 \pm 0,74 a$ \\
\hline
\end{tabular}

Médias seguidas com mesma letra na coluna não diferem entre si pelo teste de Tukey a $5 \%$ de significância.

Tabela 3 - Viabilidade (\%) das fases de larva, pupa e do período larva-adulto de Chrysoperla externa alimentada com ovos de Anagasta kuehniella, Planococcus citri e Toxoptera citricida. Temperatura de $25 \pm 1^{\circ} \mathrm{C}$, UR $70 \pm 10 \%$ e fotofase de 12 horas. Lavras, MG, 2004.

\begin{tabular}{|c|c|c|c|c|c|c|}
\hline \multirow{2}{*}{ Tratamento } & \multicolumn{3}{|c|}{ Presa consumida } & \multirow{2}{*}{$\begin{array}{l}\text { Viabilidade da } \\
\text { fase de larva }\end{array}$} & \multirow{2}{*}{$\begin{array}{l}\text { Viabilidade da } \\
\text { fase de pupa }\end{array}$} & \multirow{2}{*}{$\begin{array}{l}\text { Viabilidade } \\
\text { do período } \\
\text { larva-adulto }\end{array}$} \\
\hline & $1^{0}$ ínstar & $2^{\underline{0}}$ ínstar & $3^{-}$ínstar & & & \\
\hline 1 & A. kuehniella & A. kuehniella & A. kuehniella & $80,00 \mathrm{~A}$ & $50,00 \mathrm{~A}$ & $40,00 \mathrm{~A}$ \\
\hline 2 & P. citri & P. citri & P. citri & $70,00 \mathrm{~A}$ & $19,04 \mathrm{~B}$ & $13,33 \mathrm{~B}$ \\
\hline 3 & T. citricida & T. citricida & T. citricida & $0,00 \mathrm{C}$ & $0,00 \mathrm{C}$ & $0,00 \mathrm{C}$ \\
\hline 4 & P. citri & P. citri & T. citricida & $50,00 \mathrm{~B}$ & $40,00 \mathrm{~A}$ & $20,00 \mathrm{~A}$ \\
\hline 5 & T. citricida & P. citri & P. citri & $70,00 \mathrm{~A}$ & $14,28 \mathrm{~B}$ & $10,00 \mathrm{~B}$ \\
\hline 6 & T. citricida & T. citricida & P. citri & $56,66 \mathrm{~B}$ & $0,00 \mathrm{C}$ & $0,00 \mathrm{C}$ \\
\hline 7 & P. citri & T. citricida & T. citricida & $36,66 \mathrm{~B}$ & $0,00 \mathrm{C}$ & $0,00 \mathrm{C}$ \\
\hline 8 & P. citri & T. citricida & P. citri & $60,00 \mathrm{AB}$ & $33,33 \mathrm{AB}$ & $20,00 \mathrm{~A}$ \\
\hline 9 & T. citricida & P. citri & T. citricida & $73,33 \mathrm{~A}$ & $18,18 \mathrm{~B}$ & $13,33 \mathrm{~B}$ \\
\hline
\end{tabular}

Porcentagens seguidas das mesmas letras não diferem entre si, pelo intervalo de confiança de $95 \%$. 
adverso que esse pulgão possa ter causado às larvas de C. externa quando fornecido exclusivamente nos três ínstares. Ribeiro et al. (1991), trabalhando com a mesma espécie de pulgão, também obtiveram $100 \%$ de mortalidade de larvas desse crisopídeo, porém, as larvas não passaram do segundo ínstar. Moraes \& Carvalho (1991) e Santa-Cecília et al. (1997), fornecendo o mesmo pulgão para larvas de Ceraeochrysa cubana (Hagen, 1861) (Neuroptera: Chrysopidae), também constataram $100 \%$ de mortalidade, mas, as larvas conseguiram atingir o terceiro ínstar, conforme constatado no presente trabalho.

Embora a viabilidade das larvas alimentadas exclusivamente com $P$. citri não tenha diferido daquela obtida com ovos de A. kuehniella, pode-se pressupor que a sobrevivência nesse período poderia ser maior quando alimentadas somente com essa presa. Tais inferências se baseiam no fato de que as cochonilhas apresentam uma secreção pulverulenta de cera que recobre seu corpo, dificultando a alimentação pelas larvas de $C$. externa. Além disso, no momento da introdução das peças bucais do predador no tegumento da cochonilha, principalmente em fêmeas adultas, observou-se liberação de uma secreção geleificada através dos ostíolos laterais, caracterizada por Willians (1978) como feromônio de alarme. Essa secreção, quando em contato com o aparelho bucal do inseto, se solidificava, dificultando a capacidade de busca, com a conseqüente diminuição na capacidade predatória em razão da menor mobilidade. A larva se livrava dessa secreção somente por ocasião da ecdise.

Com relação à viabilidade da fase de pupa, o tratamento constituído pelo fornecimento de $P$. citri ao primeiro e segundo ínstares de C. externa e T. citricida ao terceiro ínstar, acarretou a maior viabilidade, não diferindo do controle. Essa dieta, embora tenha ocasionado uma viabilidade larval de $50 \%$ foi suficiente para permitir o desenvolvimento das pupas, obtendo-se uma viabilidade de $40 \%$ (Tabela 3 ). No tratamento 8 , obteve-se uma viabilidade intermediária, mantendo o mesmo efeito observado na fase larval. Ao contrário, os tratamentos 2, 5 e 9, que permitiram uma viabilidade larval significativamente maior (Tabela 3), não foram suficientes para o desenvolvimento da fase de pupa, acarretando baixa viabilidade (14\% a 19\%) nesse estágio. Santa-Cecília et al. (1997), quando forneceram Toxoptera sp. + Pinnaspis sp. para larvas de C. cubana, obtiveram uma viabilidade pupal de $15 \%$, próxima à obtida no tratamento 5 , composto por pulgões somente no primeiro ínstar e cochonilhas nos dois outros estádios. Segundo Principi \& Canard (1984), a qualidade do alimento ingerido pela larva pode interferir na viabilidade dessa fase e do período pupal, como verificado neste trabalho.

Quando o pulgão foi fornecido em ínstares sucessivos (primeiro e segundo, segundo e terceiro ou nos três ínstares do crisopídeo), a viabilidade foi de $0 \%$, ou seja, o pulgão-preto-dos-citros não foi uma presa adequada para C. externa, quando fornecido sucessivamente ao longo dos ínstares, evidenciando sua inadequabilidade ao desenvolvimento desse crisopídeo.

A viabilidade do período larva-adulto foi influenciada pelo tipo de dieta fornecida no decorrer dos ínstares. Nos tratamentos em que se forneceu o pulgão em ínstares consecutivos (primeiro e segundo, segundo e terceiro ou nos três ínstares), a viabilidade foi de $0 \%$, como constatado para a fase de pupa; porém, quando a cochonilha fez parte da dieta alimentar, a viabilidade variou de $10 \%$ a $20 \%$ (Tabela 3 ).

Cabe ressaltar que embora as larvas alimentadas com ovos de A. kuehniella tenham apresentado maior viabilidade nas fases de larva e de pupa, bem como ao longo de todo o período de larva a adulto (Tabela 3), os valores obtidos foram inferiores aos constatados em pesquisas anteriores, como mencionado por Carvalho \& Souza (2000). Tal fato pode ser atribuído à metodologia utilizada, uma vez que os ovos do piralídeo foram fornecidos sobre os discos foliares da planta cítrica, dispostos em placas de Petri contendo ágar, seguindo o mesmo procedimento empregado nos demais tratamentos. Por outro lado, nas pesquisas envolvendo o uso de ovos dessa traça como presas para larvas de crisopídeos, geralmente eles são fornecidos em recipientes desprovidos de qualquer substrato.

Entre os tratamentos constituídos por T. citricida em pelo menos dois ínstares, somente o tratamento 9 permitiu a emergência de adultos, fato que se deve, provavelmente, ao fornecimento da cochonilha no segundo ínstar do crisopídeo.

\section{CONCLUSÃO}

As presas $T$. citricida e $P$. citri fornecidas isoladamente ou de forma alternada às larvas de C. externa não se constituem em alimento adequado ao desenvolvimento do predador, em condições de laboratório.

\section{REFERÊNCIAS BIBLIOGRÁFICAS}

CARVALHO, C. F.; SOUZA, B. Métodos de criação e produção de crisopídeos. In: BUENO, V. H. P. (Ed.). Controle biológico de pragas: produção massal e controle de qualidade. Lavras: UFLA, 2000. 196 p. 
COLOSIMO, E. A. Análise de sobrevivência aplicada. In: REUNIÃO ANUAL DA REGIÃO BRASILEIRA DA SOCIEDADE INTERNACIONAL DE BIOMETRIA, 46.; SIMPÓSIO DE ESTATÍSTICA APLICADA À EXPERIMENTAÇÃO AGRONÔMICA, 9., 2001, Piracicaba. Programas e resumos... Piracicaba: ESALQ/USP, 2001. 145 p.

FREITAS, S. de. $O$ uso de crisopídeos no controle biológico de pragas. Jaboticabal: Funep, 2001. 66 p.

FREITAS, S. de. O uso de crisopídeo no controle biológico de pragas. In: PARRA, J. R. P. et al. Controle Biológico no Brasil. São Paulo: Manole, 2002. 609 p.

GONÇALVES-GERVÁSIO, R. C.; SANTA-CECÍLIA, L. V. C. Consumo alimentar de Chrysoperla externa sobre as diferentes fases de desenvolvimento de Dysmicoccus brevipes, em laboratório. Pesquisa Agropecuária Brasileira, Brasília,v. 36, n. 2, p. 387-391, fev. 2001.

GRAVENA, S. Manejo ecológico de pragas no pomar cítrico. Laranja, Cordeirópolis, v. 11, p. 205-225, 1990.

GRAVENA, S. Cochonilha-branca: descontrolada em 2001. Laranja, Cordeirópolis, v. 24, p. 71-82, 2003.

MICHAUD, J. P. A review of the literature on Toxoptera citricida (Kirkaldy). Florida Entomologist, Lutz, v. 81, p. 37-61, Mar. 1998.

MICHAUD, J. P. Evaluation o green lacewings, Chrysoperla plorabunda (Fitch) (Neurop., Chrysopidae), for augmentative release against Toxoptera citricida (Hom., Aphididae) in citrus. Journal of Applied Entomology, Berlin, v. 25, n. 7 , p. $383-388,2001$.

MORAES, J. C.; CARVALHO, C. F. Influência da fonte de carboidratos sobre a fecundidade e longevidade de
Ceraeochrysa cubana (Hagen, 1861) (Neuroptera: Chrysopidae). Ciência e Prática, Lavras, v. 15, n. 2, p. 137144, Apr./June 1991.

PRINCIPI, M. M.; CANARD, M. Feeding habits. In: CANARD, M.; SÉMÉRIA, Y.; NEW, T. R. Biology of Chrysopidae. The Hague: Dr. W. Junk, 1984. v. 4, p. 76-92.

RIBEIRO , M. J.; CARVALHO, C. F.; MATIOLI, J. C. Influência da alimentação larval sobre a biologia de adultos de Chrysoperla externa (Hagen, 1861) (Neuroptera: Chrysopidae). Ciência e Prática, Lavras, v. 5, n. 4, p. 349354, out./dez. 1991.

SANTA-CECÍLIA, L. V. C.; SOUZA, B.; CARVALHO, C. F. Influência de diferentes dietas em fases imaturas de Ceraeochrysa cubana (Hagen) (Neuroptera: Chrysopidae). Anais da Sociedade Entomológica do Brasil, Piracicaba, v. 26, n. 2, p. 309-314, ago. 1997.

SOUZA, B. Estudos morfológicos do ovo e da larva de Chrysoperla externa (Hagen, 1861) (Neuroptera: Chrysopidae) e influência de fatores climáticos sobre a flutuação populacional de adultos em citros. 1999. 141 p. Tese (Doutorado em Agronomia/Entomologia) Universidade Federal de Lavras, Lavras, 1999.

SOUZA, B.; CARVALHO, C. F. Population dynamics and seasonal occurrence of adults of Chrysoperla externa (Hagen, 1861) (Neuroptera: Chrysopidae) in a citrus orchard in Southern Brazil. Acta Zoologica Academiae Scientiarum Hungaricae, v. 48, n. 2, p. 301-310, 2002. Supplement.

WILLIANS, D. J. The anomalous ant-attended mealy bugs (Homoptera: Pseudococcidae) of southern Asia. Bulletin of the British Museum (Natural History) Entomology, London, v. 37, p. 1-72, 1978. 